\title{
The influence of oral contrast agent on pelvic VMAT dose in patients with postoperative endometrial carcinoma
}

Wenwen Bai ${ }^{1}$, Ruohui Zhang ${ }^{2}$, Xiaomei Fan ${ }^{3}$,Qianying Zhang ${ }^{3}$, Mingchang Miao², Zifeng Chi². ${ }^{1}$ Department of Radiation Ocology, The Fourth Hospital of Hebei Medical University, Shijiazhuang 050011, China; ${ }^{2}$ Department of Radiation Therapy, The Fourth Hospital of Hebei Medical University, Shijiazhuang 050011, China; ${ }^{3}$ Department of Gynecological Oncology, the Fourth Hospital of Hebei Medical University, Shijiazhuang 050011, China

Purpose: Recently, with the introduction of the advanced Volume modulated arc therapy (VMAT) delivery systems used for patient treatment, which places even greater demands on delivering accuracy. To evalutate the impact of oral contrast agent (meglumine diatrizoate) for assisting in outlining the small intestine on pelvic volume modulated arc therapy (VMAT) dose in patients with endometrial carcinoma. Methods: Ten endometrial carcinoma patients for postoperative radiotherapy underwent CT scans, and the planning target volumes (PTV) and organs at risk (including the small intestine, rectum, bladder, colon and the left and right femoral head) were contoured. The VMAT plans were generated on Oncentra v4.1 planning system for each case, PTV was prescribed to $50.4 \mathrm{~Gy}$ in 28 fractions. Then another plan was generated by re-calculating the radiation dose after changing the electron density of the small bowel. The first plan (plan A) was the conventional VMAT plan (with oral contrast agent), and the second one (plan B) specified the electron density of the small bowel (without oral contrast agent). Paired t-test was used to compare the dose distribution between the two plans. Results: The PTV's D2, D50, D95, V110,homogeneity index $(\mathrm{HI})$ and fonformity index $(\mathrm{Cl})$ of plans $\mathrm{A}$ and $B$ were 5615.5 vs. 5618.4 cGy $(P=0.18), 5350.1$ vs. 5354.0 cGy $(P=0.875), 5042$ vs. $5045.4 \quad(P=0.52), 6.1 \%$ vs. $6.2 \%($ $\mathrm{P}=0.888), 0.127$ vs. $0.1272(\mathrm{P}=0.34)$ and 0.842 vs. 0.842 $(\mathrm{P}=0.61)$, respectively. The volumes of the small bowel receiving at least 30 Gy (V30) and the minimum dose of $2 \%$ volume accepted (D2) for plans $A$ and $B$ were $32.1 \%$ vs. $31.8 \%$ $(P=0.375)$ and 5075.8 vs. 5090.4 cGy $(P=0.383)$, while rectum $\mathrm{V} 50$ of the two plans was $12.5 \%$ vs. $12.2 \%(\mathrm{P}=0.49)$.
The analysis results as Table 1. And the treatment plan A and $B$ were imported into the CERR software to analysis the dose volume histogram see Fig1.

Conclusion: The oral contrast agent (meglumine diatrizoate) filling the small intestine does not lead to a significant increase in the pelvic VMAT dose in patients with postoperative endometrial carcinoma.

Table 1. The dosimetric parameters comparison of VMAT plans with and without oral contrast agent Impact $(x \pm s)$

\begin{tabular}{|c|c|c|c|c|c|c|c|c|}
\hline plan & HI (PTV) & CI (PTV) & D2 (PTV) & D50 (PTV) & $\begin{array}{l}\mathrm{D} 95 \text { (PTV) } \\
\text { (cGy) }\end{array}$ & $\begin{array}{c}\mathrm{D} 98(\mathrm{PTV}) \\
(\mathrm{cGy})\end{array}$ & $\begin{array}{c}\mathrm{V} 110(\mathrm{PTV}) \\
(\mathrm{cGy})\end{array}$ & $\begin{array}{c}\text { D2 (Cord) } \\
\text { (cGy) }\end{array}$ \\
\hline Plan A & $\begin{array}{l}0.127 \pm 0.01 \\
794\end{array}$ & $\begin{array}{c}0.842 \pm 0.02 \\
091\end{array}$ & $\begin{array}{c}5615.5 \pm 90 . \\
6\end{array}$ & $\begin{array}{c}5350 . \\
2\end{array}$ & $\begin{array}{c}5042 \pm 0.1 \\
5\end{array}$ & 4932. $2 \pm 6.2$ & $6.1 \pm 5.6$ & $\begin{array}{l}3791.1 \pm 10 \\
1.6\end{array}$ \\
\hline Plan B & $\begin{array}{c}0.1272 \pm 0.0 \\
182\end{array}$ & $\begin{array}{c}0.842 \pm 0.01 \\
985\end{array}$ & $\begin{array}{c}5618.4 \pm 90 . \\
1\end{array}$ & $5354.0 \pm 41$. & $\begin{array}{c}5045.4 \pm 7 \\
.6\end{array}$ & $4932.1 \pm 6.9$ & $6.2 \pm 5.5$ & $\begin{array}{l}3792 \pm 102 . \\
3\end{array}$ \\
\hline $\mathrm{t}$ value & -1.234 & 0.621 & -2.065 & 0.187 & -0.777 & 0.045 & -0.163 & -0.453 \\
\hline$P$ value & 0.34 & 0.61 & 0.18 & 0.875 & 0.52 & 0.968 & 0.888 & 0.695 \\
\hline
\end{tabular}

\begin{tabular}{|l|l|l|l|l|l|l|l|}
\hline plan & V40(Rectum) (\%) & v50(Rectum) & $\begin{array}{c}\text { V40(Bladder) } \\
(\%)\end{array}$ & $\begin{array}{l}\text { V50(Bladder) } \\
(\text { () }\end{array}$ & V30(Bowel) (\%) & D2(Bowel) (\%) & D2 (Colon) (\%) \\
\hline Plan A & $43.3 \pm 3.3$ & $12.4 \pm 1.9$ & $40.3 \pm 3.6$ & $16.4 \pm 8.6$ & $31.6 \pm 8.5$ & $5067.8 \pm 77.4$ & $5565.1 \pm 175.4$ \\
\hline Plan B & $43.4 \pm 3.4$ & $12.1 \pm 2.4$ & $40.3 \pm 3.6$ & $16.5 \pm 8.5$ & $31.9 \pm .8 .3$ & $5085.4 \pm 65.2$ & $5583.3 \pm 158.4$ \\
\hline t value & -1.82 & 0.84 & -1 & -1 & -1.14 & -1.12 & -1.111 \\
\hline P value & 0.21 & 0.489 & 0.423 & 0.423 & 0.371 & 0.377 & 0.382 \\
\hline
\end{tabular}

\begin{tabular}{|c|l|l|l|l|l|}
\hline plan & \multicolumn{1}{|c|}{ Average Rectum } & \multicolumn{1}{|c|}{ Average Bladder } & \multicolumn{1}{|c|}{ Average bovel } & \multicolumn{1}{|c|}{ Average colon } & \multicolumn{1}{|c|}{ Average cord } \\
\hline Plan A & $3738.3 \pm 310.6$ & $3914 \pm 189.2$ & $2471.3 \pm 337.9$ & $4373.3 \pm 462.1$ & $823.3 \pm 273.7$ \\
\hline Plan B & $3938.7 \pm 103.7$ & $3914.3 \pm 188.8$ & $2472 \pm 3334.2$ & $4373 \pm 459.2$ & $823 \pm 273.2$ \\
\hline $\mathrm{t}$ value & -1.002 & -1 & -0.286 & 0.2 & 1 \\
\hline P value & 0.422 & 0.423 & 0.802 & 0.860 & 0.423 \\
\hline
\end{tabular}

V90 is the volume which the target volume irradiated $90 \%$ prescription dose, $\mathrm{V} 95$ and so on

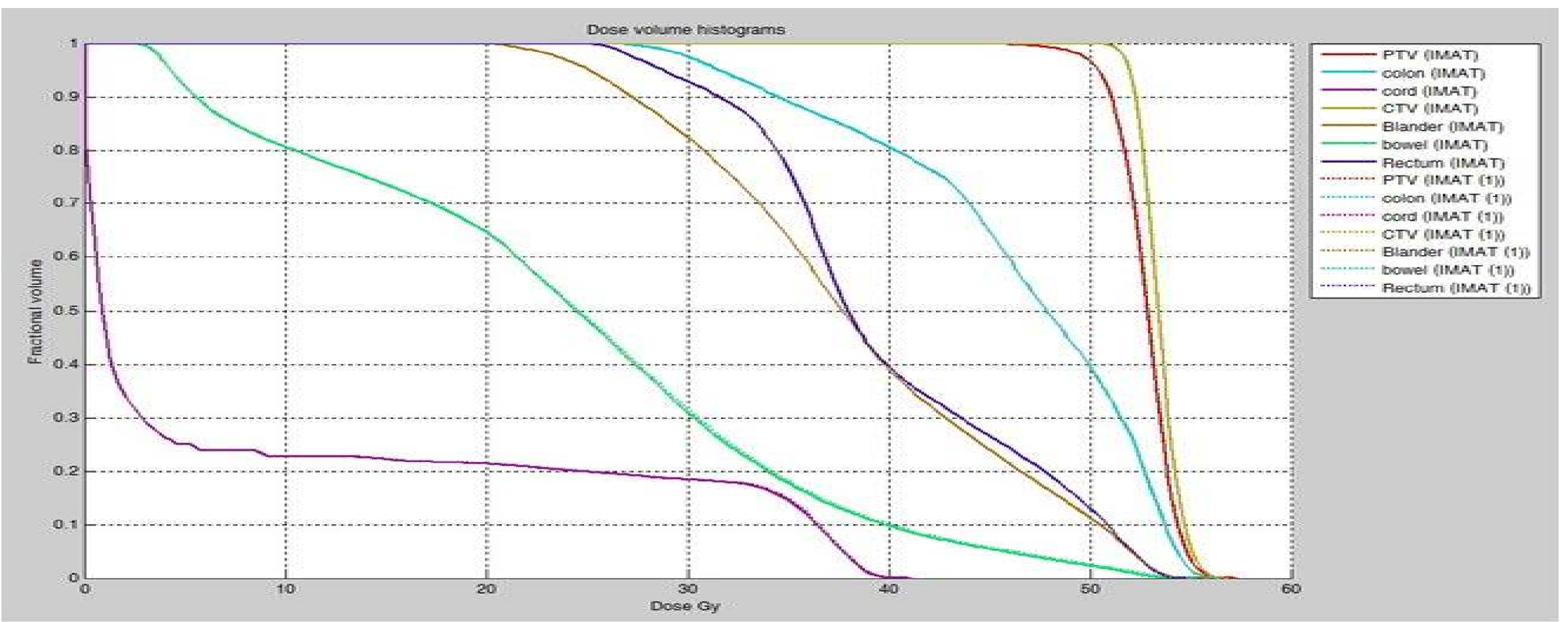

Fig 1. The DVH comparison Plan A vs.Plan B. The solid line is pan A (with oral contrast agent influence) and the dotted line is Plan B (without oral contrast agent influence) 